Proceedings of the International Scientifical Conference. Volume II: Social and Special pedagogy; Health and Sport; Overviews.

\title{
SOME STRATEGIES OF THE EFFECTIVE TEACHING OF FOREIGN LANGUAGES
}

\author{
Dažas svešvalodas mācīšanas efektīvas stratēgeijas
}

\author{
Irina Gvelesiani \\ Ivane Javakhishvili Tbilisi State University, Georgia \\ E-mail: irinagvelesiani@yahoo.com
}

\begin{abstract}
Nowadays, under the influence of drastic changes of the contemporary world, the institutions of higher education focus on the promotion of equity and quality. Special attention is paid to the cross-border education, bacause the mobility of students and staff facilitates the „formation" of highly skilled workers in certain specialized areas. The main precondition of a successful implementation of mobility programs is a profound knowledge of foreign languages. The given paper deals with the importance of second language acquisition and outlines the strategies of a successful teaching process. The main emphasis is put on the "enhancement" of students' motivation (including a good teacher-student rapport) and teaching a language through teaching a culture. The first one is regarded as a key element of a classroom success, while the latter simplifies learners' comprehension of second language reality.
\end{abstract}

Keywords: acquisition, culture, globalization, higher education, motivation.

Nowaday, globalization acquires more and more importance in today's world. It makes all the existed boarders and boundaries irrelevant and facilitates cultural, political, economic and environmental interconnections, which push people closer together through highly developed international trade and commerce, education exchange, rapid transportation and communication. The process of globalization has interfered into many spheres of life: "globalization together with new information technology and the innovative processes they foment are driving a revolution in the organization of work, the production of goods and services, relations among nations, and even local culture... it is changing the very fundamentals of human relations and social life" (Carnoy M., 2005).

Drastic changes are seen in the sphere of economy. Technology, capital, management, information, core markets - everything is globalized. "Governments in a global economy need to stimulate investment, including, in most countries, foreign capital and increasingly knowledge intensive capital, which means providing a ready supply of skilled labor" (Carnoy M., 2005). In the context of the "globalized economy", higher education has become a market-determined process, which has undergone a tremendous expansion in the recent past. "An expanded higher education sector has become a necessary condition for a country's growth in the present environment; it is important in promoting faster technological catch-up and in improving a country's ability to maximize economic output" (Carnoy M., 2005). One of the key factors of such expansion is the increasing employment opportunities for the university graduates and the greatest demand of skilled professionals in every field of rapidly developing economy. Moreover, in the context of globalization, more and more people are investing their time and money 
in acquiring an appropriate knowledge - a skilled individual functions successfully in the global scale.

In the ,atmosphere" of the ongoing changes, the institutions of higher education focus on the promotion of equity and quality. Special attention is paid to the cross-border education, bacause the cross-boarder mobility of students and staff facilitates the „formation” of highly skilled workers in certain specialized areas. The main precondition of a successful implementation of mobility programs is a profound knowledge of foreign languages. Therefore, all the institutions of higher education are focused on the promotion of second language acquisition.

The given paper deals with the necessity of foreign language acquisition and outlines the main strategies of the effective process of teaching.

It's difficult to identify a precise date when the field of second language acquisition research appeared. Modern linguistic studies indicate mid-1960s. Hence, the term "acquisition" was popularized by a well-known American linguist Stephen Krashen. His Acquisition-Learning hypothesis has gained the greatest popularity and is widely known among language practitioners and linguists. The given hypothesis differentiates two independent ways in which individuals develop their linguistic skills: "the acquired system" (acquisition) and "the learned system" (learning).

"The acquired system" is the product "of a subconscious process very similar to the process children undergo when they acquire their first language. It requires meaningful interaction in the target language - natural communication - in which speakers are concentrated not in the form of their utterance, but in the communicative act" (Stephen...).

On the other hand, "the learned system" or learning a language is a conscious process like what a pupil experiences at school. "New knowledge or language forms are represented consciously by learner's mind, frequently in the form of language "rules" and "grammar" and the process often involves error correction" (Krashen, 2006). According to Krashen's point of view, learning is less effective than acquisition, because only a subconscious process can lead to fluency. Hence, nowadays, for most scholars "language learning" and "language acquisition" are interchangeable terms (unless they are directly addressing Krashen's work). Moreover, Krashen's theory is regarded as one of various techniques of cognitive theory for language learning.

It's worth mentioning, that early researches in the field of second language acquisition were focused on differences between the native (first) language and second language to predict the areas of difficulty for the learners. Subsequent studies were oriented on universal grammar, while current researches are dedicated to the question of the improvement of techniques of language education. A special attention is paid to such factors as:

- the effect of first language on the second language learning;

- motivation of the learner;

- age and background of the learner;

- the environment in which the second language is being learnt. 
Proceedings of the International Scientifical Conference. Volume II: Social and Special pedagogy; Health and Sport; Overviews.

There have been a lot of debates among scholars about the impact of first language on the process of second language acquisition. Language researchers such as Jim Cummins, Catherine Snow, Lily Wong Filmore and Stephen Krashen have studied this question for several years. According to the scholars' consensus the length and success of second language acquisition greatly depends on the knowledge of first language. Furthermore, the individuals who have strong language and literacy skills need between five to seven years to achieve advanced fluency. For some persons acquiring a second language can be a lifelong learning process. Despite persistent efforts, most learners of a second language never become fully native-like in it, although a lot of practice facilitates the achievement of considerable fluency.

One more aspect, which must be taken into consideration during the teaching of the second language is students' motivation, which is usually defined as the learners' energy and drive to try hard, study effectively and do the best for achieving better results. It's believed, that motivation is a key element facilitating a successful teaching process. Language researchers created "The Motivation and Engagement Wheel", which comprises: positive thoughts, positive behaviors, negative thoughts and negative behaviors.

"Positive thoughts include:

- self-belief

- valuing school

- Learning focus

Positive behaviors include:

- Planning

- Task management

- Persistence

Negative thoughts include:

- Anxiety

- Failure avoidance

- Uncertain control

Negative behaviors include:

- Self-handicapping

- Disengagement" (Martin, A., 2010)

It's believed, that positive thoughts and behaviors boost students' motivation, while negative thoughts reduce their achievements. Motivation can even be learnt and changed. Therefore, a lot depends on the educator, whose skillful approach to the development of positive strategies (self-belief, persistence, learning focus, task management) and the rejection of negative ones (students' anxiety, failure avoidance, disengagement) helps students to feel optimistic, to get better results, to do difficult class-work confidently and enjoy student life. Moreover, a good teacher - student rapport (teacher - student relationship) is regarded as a key, that "opens up a comfortable space for more learning 
opportunities, allowing students to increase their participation in the classroom as a community of practice" (Lave\&Wenger, 1991) that obviously leads to better achievements.

One more aspect, which must be taken into consideration during the teaching of the second language is the relationship between language and culture. According to the generally accepted assumption, this relationship is deeply rooted. Language is usually defined as a system of arbitrary vocal symbols used for human communication. Culture is considered as an "integrated pattern of human behavior that includes thoughts, communications, languages, practices, beliefs, values, customs, courtesies, rituals, manners of interacting and roles, relationships and expected behaviors of a racial, ethnic, religious or social group; and the ability to transmit the above to succeeding generations"

Different scholars have expressed different ideas about the relationship between language and culture. Even early anthropologists believed, that language and its structure were entirely dependent on the cultural context in which they existed. Many linguists recognized, that the forms and uses of a particular language reflected the cultural values of the society in which that language was spoken. At the end of the $20^{\text {th }}$ century Emmitt and Pollock argued, that people which were brought up under similar behavioral backgrounds and cultural situations, but spoke different languages could have very different world views. The most influential statement was made by the American linguists Edward Sapir and Benjamin Whorf. According to their point of view:

"Man's language moulds his perception of reality. We see the world in the way that our language describes it, so that the world we live in is a linguistic contrast" (The relationship...).

Sapir-Whorf's hypothesis gained the greatest popularity. Its two major components - linguistic determinism and linguistic relativity - were discussed by various scholars and philosophers. Hence, many of them rejected linguistic determinism (holding the following idea - the way one thinks is determined by the language one speaks, because one can only perceive the world in terms of the categories and distinctions encoded in the language) and argued, that if language determined the thought totally and if there was no thought without language, speakers of different languages would never understand each other. Despite such rejection almost all the scholars have admitted, that language influences thought and culture. On the one hand, it is the means of maintaining and conveying culture and cultural ties. On the other hand, language is heavily influenced by culture, which comes up with new ideas and develops language components to express them.

From this, one can see that learning a new language involves learning a new culture. Teachers of a particular language are also the teachers of a particular culture. They have to acknowledge, that culture is a much broader concept which is inherently tied to many linguistic concepts taught in second language classes. Linguistic competence alone is not enough for learners of a language to be competent in that language. Students cannot truly master the language until they 
Proceedings of the International Scientifical Conference. Volume II: Social and Special pedagogy; Health and Sport; Overviews. have also mastered the cultural contexts in which the language occurs (National Standards in Foreign Language Education Project, 1996). Therefore, language educators have to incorporate the study of culture into their classroom curricula and focus on the following strategies:

- Comprehend culture as the total accumulation of beliefs, customs, values, behaviors and communication patterns that are shared and passed down from generation to generation;

- Identify key cultural items in every aspect of the taught language. Therefore, experience culture through language;

- Inform students (via giving clues and background information) about objects and ideas that are specific to the culture of study but are unfamiliar to their cultural reality;

- Allow students to observe and explore cultural interactions from their own perspectives for finding their own voices in the second language speech community.

For the implementation of the above mentioned strategies: "language teachers must instruct their students on the cultural background of language usage, choose culturally appropriate teaching styles, and explore culturally based linguistic differences to promote understanding instead of misconceptions or prejudices" (Culture...). Culture must be fully incorporated as a vital component of language learning. Therefore, teaching language without teaching the culture in which it operates means learning empty or meaningless symbols. For the promotion of the effective teaching process:

- Culture and cultural features must be taught not only implicitly (embedded in the linguistic forms), but explicitly - through the explicit topics of discussion during the classroom activities;

- $\quad$ Students must be engaged in authentic cultural experience via the usage of authentic sources (films, news broadcasts, television shows, travel brochures, newspapers, photographs, restaurant menus, online material, ect.) from the native speech community. Authentic materials must suit students' age and level of language proficiency.

Therefore, the given paper deals with the importance of second language acquisition and outlines the strategies of a successful teaching process. The main emphasis is put on the "enhancement" of students' motivation (including a good teacher-student rapport) and teaching a language through teaching a culture. The first one is regarded as a key element of a classroom success, while the latter simplifies learners' comprehension of second language reality.

\section{Summary}

Nowadays, drastic changes are seen in the sphere of economy. Technology, capital, management, information, core markets - everything is globalized. In the context of the "globalized economy", higher education has become a marketdetermined process, which has undergone a tremendous expansion in the recent 
past. In the ,atmosphere” of the ongoing changes, the institutions of higher education focus on the promotion of the cross-border education, bacause mobility of students and staff facilitates the „formation” of highly skilled workers in certain specialized areas. Therefore, the greatest attention is paid to the question of second language acquisition. The improvement of the techniques of language education becomes the sphere of interest of many scholars and educators. According our point of view, the best results can be achieved by considering such significant factors as:

- the effect of first language on the second language learning;

- motivation of the learner;

- $\quad$ age and background of the learner;

- incorporation of cultural knowledge into the process of language learning.

A special attention must be paid to the last factor, because linguistic competence is not enough for learners to be competent in the foreign language. Students cannot truly comprehend foreign reality and therefore, master the language until they have also mastered the cultural contexts in which the language occurs. Moreover, culture and cultural features must be taught not only implicitly (embedded in the linguistic forms), but explicitly.

\title{
Bibliography
}

1. Carnoy, M. Globalization, educational trends and the open society, OSI Education Conference 2005: „Education and Open Society: A Critical Look at New Perspectives and Demands" http://www.soros.org/initiatives/esp/articles_publications/articles/globalization_2006021 7/carnoy_english.pdf)

2. Culture in second language teaching $\mathrm{http} / / / \mathrm{www} . c a l . o r g /$ resources/digest/0309peterson.html

3. Krashen, S. (2003). Explorations in Language Acquisition and Use Portsmouth, Heinemann.

4. Lave, J. and Wenger, E. (1991). Situated Learning: Legitimate Peripheral Participation. Cambridge: Cambridge University Press.

5. Martin, A. (2010). Positive and practical strategies for building classroom success and student motivation, 2010 www.lifelongachievement.com/Building\%20Success\%20and \%20 motivation.pdf.

6. Stephen Krashen's Theory of Second Language Acquisition http://www.sk.com.br/sk-krash. html.

7. The relationship between language and culture and its pedagogical implications (http://lang-8.com/28968/journals/81125)

\author{
Irina Gvelesiani Ivane Javakhishvili Tbilisi State University, \\ Faculty of Humanities \\ Chavchavadze Ave. 36, Tbilisi, Georgia. \\ E-mail: irinagvelesiani@yahoo.com \\ Phone: +995593327007
}

